\title{
Background predictors of time to death in infancy: evidence from a survival analysis of the 2018 Nigeria DHS data
}

\author{
Michael Kunnuji ${ }^{1}$, Idongesit Eshiet ${ }^{1}$, Bright Opoku Ahinkorah ${ }^{2}$, Temitope Omogbemi ${ }^{1}$ and Sanni Yaya ${ }^{3,4^{*}}$ (i)
}

\begin{abstract}
Background: Nigeria's child health profile is quite concerning with an infant mortality rate of 67 deaths per 1000 live births and a significant slowing down in progress towards improving child health outcomes. Nigeria's 2018 Demographic and Health Survey (DHS) suggests several bio-demographic risk factors for child death, including mother's poor education, poverty, sex of child, age of mother, and location (rural vs urban) but studies are yet to explore the predictive power of these variables on infant survival in Nigeria.

Methods: The study extracted data for all births in the last 12 months preceding the 2018 Nigeria DHS and used the Cox proportional hazard model to predict infant survival in Nigeria. Failure in this analysis is death with two possible outcomes - dead/alive - while the survival time variable is age at death. We censored infants who were alive at the time of the study on the day of the interview. Covariates in the analysis were: age of mother, education of mother, wealth quintile, sex of child, location, region, place of delivery, and age of pregnancy.
\end{abstract}

Results: The study found that a higher education of a mother compared to no education ( $\beta=.429$; $p$-value $<0.05)$; belonging to a household in the richer wealth quintile $(\beta=.618$; $p$-value $<0.05)$ or the highest quintile $(\beta=.553$; $p$-value $<0.05)$, compared to the lowest wealth quintile; and living in North West $(\beta=1.418 ; p$-value $<0.05)$ or South East zone $(\beta=1.711 ; p$-value $<0.05)$, significantly predict infant survival.

Conclusion: Addressing Nigeria's infant survival problem requires interventions that give attention to the key drivers - education, socio-economic status, and socio-cultural contextual issues. We therefore recommend full implementation of the universal basic education policy, and child health education programs targeted at mothers as long- and short-term solutions to the problem of poor child health outcomes in Nigeria. We also argue in favor of better use of evidence in policy and program development in Nigeria.

Keywords: Time to death in infancy, Survival analysis, Nigeria: DHS, Global Health

\section{Background}

Globally, the past two decades have been marked by significant decline in neonatal, infant and under-five mortality rates [1]. Recent Demographic and Health Surveys

\footnotetext{
*Correspondence: sanni.yaya@uOttawa.ca

${ }^{3}$ School of International Development and Global Studies, Faculty of Social Sciences, University of Ottawa, 120 University Private, Ottawa, ON K1N 6N5, Canada

Full list of author information is available at the end of the article
}

(DHS) in Nigeria show that the decline in child mortality rates is slowing down. While the country recorded a decline from 201 under-five deaths per 1000 live births in 2003 to 157 in 2008 and 128 in 2013, the rate rose slightly to 132 deaths per 1000 live births in 2018. A similar trend was recorded in neonatal mortality rate which declined from 48 deaths per 1000 live births in 2003 to 40 in 2008 and 37 in 2013 only to rise slightly to 39 in 2018. Significant gains were also recorded in infant mortality rates 
which declined from 100 deaths per 1000 live births to 75 deaths between 2003 and 2013. It further declined to 69 in 2013, but between 2013 and 2018, infant mortality barely declined, with a 2018 rate of 67 deaths per 1000 live births [2].

At present, more than half a million Nigerian infants die yearly (United Nations Inter-Agency Group for Child Mortality Estimation (UN IGME), 2019) and achieving the Sustainable Development Goal (SDG 3) target of reducing neonatal mortality rate and under-five mortality rate to 12 and 25 deaths per 1000 live births respectively by 2030 [3] may be unattainable on current trends. Repositioning Nigeria on the path of steady and sustained child mortality decline requires applying strong scientific evidence in revising the country's child health policy and programs. Nationally representative surveys in Nigeria have consistently shown subnational variation and biodemographic factors by which rates vary significantly among sub-populations [2, 4]. If this variation is sufficiently understood, programs based on such evidence may yield better results as they would be designed to target sub-populations with the most needs.

The DHS reports show some 'biodemographic risk factors' for child mortality but there is need for analysis using models that allow for variable control. Mother's education, wealth, sex of child, age of mother, and location (rural vs urban) are associated with the death/survival of a child [2]. This study builds on this to show the predictors of child death in infancy when hazard ratios are adjusted in a model with multiple covariates. It is known, for instance, that education and wealth are significant predictors of several variables such as location and place of delivery which may influence child survival [2]. What we do not know yet is whether location and place of delivery are predictors of child survival if education and wealth are held constant using recent nationally representative data. In addition, do variables such as the sex of a child, a mother's age, duration of pregnancy and region predict the occurrence of death in infancy among Nigerian children? Answering these questions holds much for effective programming to reduce infant mortality and improve Nigeria's child health policy.

Proximate predictors of child deaths include sociodemographic factors [5-8], biomedical factors such as birth interval, weight and gestation period, sex of child and diseases [9-16] and health-seeking behavior and barriers to care $[17,18]$. Research shows that education, income, and access to healthcare resources (including safe drinking water and sanitation) enhance child survival globally $[5-8,10,15,19,20]$, and countries having higher inequality in access to education, income and healthcare resources also have higher mortality rates $[5,8]$. Other predictors include region/geographic inequalities [19-22], age of mother (at first birth/current) $[20,21]$ and health-seeking behavior for children, with the use of facility-based care for delivery and child illness leading to improved child survival [22-25]. Use of facility-based care is itself influenced by factors like location, education, socioeconomic status, and socio-cultural context [25-30].

In summary, previous studies show that different categories of nonbiomedical and biomedical predictors of child death may exist, including socio-demographic factors such as wealth, education, location, age of mother, sex of child, gestational period, and health seeking behavior. This study's primary objective is to show how mother's education, household poverty, sex of child, age of mother, and location (whether rural or urban), place of delivery and whether pregnancy is pre- or full-term predict the survival of infants in Nigeria. It is important to know whether these factors continue to predict child survival even as infant mortality continues to decline slowly. While the DHS report implies that sex of child, age of mother and location (rural vs urban) are predictors of child survival, this study seeks to show whether these variables retain their predictive power in a survival analysis of infants with multiple covariates. It is possible for infant mortality to appear to be associated with or predicted by single variables when not controlling for confounding effects of other variables. For instance, living in a rural area appears to be a significant predictor of infant death in the DHS report with an infant mortality rate of 56 deaths per 1000 live births, compared to a rate of 74 deaths per 1000 live births in urban settlements. Other variables such as mother's education and household wealth may be responsible for this observation and living in a rural area may not increase the risk of infant death. The current study addresses this problem.

\section{Methods}

\section{Data source}

The data used for this study came from the 2018 Nigeria DHS which was implemented by the National Population Commission [Nigeria] with technical support from ICF International through the DHS Program, between August and December 2018. The DHS used Nigeria's most recent census data as a sampling frame to achieve a nationally representative sample of women 15-49years. The study adopted a stratified sampling technique which identified two strata - rural and urban - in each of Nigeria's 36 states and the Federal Capital Territory, resulting in a total of 74 strata. A total of approximately 42,000 households were selected for the study and all eligible women (resident or stayed in the household the night preceding the interview) in selected households were included in the study. A total of 41,821 women were interviewed. The 
DHS questionnaire, which has a section on birth history and child mortality, was administered in the local languages - Hausa, Igbo, and Yoruba - by specially trained data collectors using computer-assisted personal interviewing devices [2]. The birth data file contains 127,545 cases from which 7700 births that occurred within 12 months prior to the DHS interviews were selected for analysis.

\section{Data extraction and selection of variables}

The failure event in the analysis is death while the survival time is the age of infant in months at the time of death. Living children were right censored at the time of the interview. The independent variables in the study are mother's education, wealth quintile, place of residence (urban vs rural), region, mother's age, child's sex, duration of pregnancy and place of birth. Mother's education was recoded into four categories. 'Some primary education' and 'completed primary education' were merged, and 'some secondary education' and 'completed secondary education' categories were merged. Mother's age was recoded into three categories - teenage mothers (<20years), 20-39years and 40-49years. The duration of pregnancy was recoded into pre-term (less than 37 weeks) and full term (37 weeks or more). We recoded place of delivery into two categories - facility delivery (government hospitals, health centers, health posts and other public facilities, private hospitals, and clinics); and home delivery (which includes mother's homes, and other places (representing 1.47\% of all cases) such as spiritual and traditional birth attendants' places. All other variables were used in the form which they originally appeared in the DHS data.

\section{Statistical analysis}

Univariate analysis was carried out for the socio-demographic characteristics and child survival. Next, we used Pearson's chi-square test of independence to determine bivariate associations between child survival and the socio-demographic characteristics. Finally, we employed the Cox proportional hazards model which models time to a failure (death) using the formula:

$$
(h)(\mathrm{t})=h_{0}(t) \exp \left(\beta_{1} x_{1}+\cdots+\beta_{k} x_{k}\right.
$$

where: $h(\mathrm{t})$ represents the hazard of a failure (death); $h_{0}$ represents the baseline hazard; and $\beta_{\mathrm{k}}$ represents the coefficients of the covariates - mother's education, wealth quintile, age, region, location, sex of child, duration of pregnancy, and place of delivery. The analysis includes both unadjusted and adjusted hazard ratios at 95\% confidence intervals (CI). For all the covariates, the first categories were used as the reference categories. The analysis was done with Stata Version 16.

\section{Ethics approvals}

Ethics approval was not required for this study since the data is secondary and is available in the public domain. More details regarding DHS data and ethical standards are available at: http://goo.gl/ny8T6X.

\section{Results}

A little more than half (51\%) of the births were male births. Only $1 \%$ of the births were pre-term births (less than 37 weeks). More than half of the births (53\%) happened in mothers' homes. Births in government health centers, government hospitals and private hospitals/clinics represented 14, 13 and $12 \%$, respectively. The ages of mothers of children included in the study ranged from 15 to 49 years, with a mean of 27.9 years ( $\mathrm{SD}=6.8$ years). About $45 \%$ of the mothers had no formal education, and almost a third (32.8\%) had secondary education while $7 \%$ had higher education. Most of the births occurred in the northern geopolitical zones with the North Central, Northeast and Northwest accounting for 18, 21 and $32 \%$, respectively; and the Southeast, South South and Southwest accounting for 11,9 and $10 \%$, respectively. About two-thirds $(67 \%)$ of the births occurred in rural areas, and women in lower wealth quintiles accounted for most of the births, the lowest, second and third quintiles accounting for 23,24 and $22 \%$ of the births, respectively. About $12 \%$ of the children died.

As presented in Table 1, about three of every five infant deaths (59\%) occurred before the first month, typically around the time of birth. Socio-demographic variables associated with dying included mother's education $\left(X^{2}=35.3001 ; P=0.000\right)$; wealth quintile $\left(X^{2}=37.4980\right.$; $P<0.000)$; location $\left(\mathrm{X}^{2}=18.7750 ; \mathrm{P}=0.000\right)$; duration of pregnancy $\left(\chi^{2}=213.5547 ; P<0.001\right)$; and place of delivery $\left(X^{2}=9.0915 ; P=0.003\right)$. Child death was associated with low education, being poor, living in a rural community, pre-term birth and home delivery.

A major predictor of the occurrence of failure (death) in infants is education when other variables in the model are controlled as Table 2 shows. While children born by mothers with primary and secondary education do not differ significantly from those without formal education in likelihood of failure, infant death adjusted hazard ratios are significantly lower for children of mothers with higher education $(\mathrm{aHR}=.429$; $p$-value <0.05). Table 2 further shows significantly lower adjusted hazard ratios for children in the fourth quintile $(\mathrm{aHR}=.618 ; p$-value $<0.05)$ and the highest quintile $(\mathrm{aHR}=.553 ; \mathrm{p}$-value $<0.05)$. Infants in the Northwest have a significantly higher adjusted hazard 
Table 1 Child survival by socio-demographic characteristics

\begin{tabular}{|c|c|c|c|c|}
\hline & Child alive & Child dead & Total & $x^{2} ; p$-values \\
\hline Age of mother & & & & $x^{2}=0.6859 ; p=0.710$ \\
\hline 15-19years & $573(88.15)$ & $77(11.85)$ & $650(100)$ & \\
\hline 20-39years & $5776(87.8)$ & $804(12.2)$ & $6580(100)$ & \\
\hline 40-49years & $407(86.6)$ & $63(13.4)$ & $470(100)$ & \\
\hline Education & & & & $x^{2}=35.3001 ; p<0.001$ \\
\hline No formal education & $2962(85.8)$ & $492(14.2)$ & $3454(100)$ & \\
\hline Completed/some primary education & 1007 (86.6) & $156(13.4)$ & $1163(100)$ & \\
\hline Completed/some secondary education & $2273(90.1)$ & $249(9.9)$ & $2522(100)$ & \\
\hline Higher education & $514(91.6)$ & $47(8.4)$ & $561(100)$ & \\
\hline Wealth & & & & $x^{2}=37.4980 ; p<0.001$ \\
\hline Lowest quintile & $1506(85.4)$ & $257(14.6)$ & $1763(100)$ & \\
\hline Second quintile & $1586(86.2)$ & $254(13.8)$ & $1840(100)$ & \\
\hline Third quintile & $1441(87.2)$ & $212(12.8)$ & $1653(100)$ & \\
\hline Fourth quintile & $1279(90.5)$ & $134(9.5)$ & $1413(100)$ & \\
\hline Highest quintile & $944(91.6)$ & $87(8.4)$ & $1031(100)$ & \\
\hline Region & & & & $x^{2}=47.0126 ; p<0.001$ \\
\hline North Central & $1198(88.8)$ & $151(11.2)$ & $1349(100)$ & \\
\hline Northeast & $1407(86.5)$ & $220(13.5)$ & $1627(100)$ & \\
\hline Northwest & 2074 (84.9) & $369(15.1)$ & $2443(100)$ & \\
\hline Southeast & $753(90.0)$ & $84(10.0)$ & $837(100)$ & \\
\hline South South & $648(91.8)$ & $58(8.2)$ & $706(100)$ & \\
\hline Southwest & $676(91.6)$ & $62(8.4)$ & $738(100)$ & \\
\hline Place of residence & & & & $x^{2}=18.7750 ; p<0.001$ \\
\hline Urban & $2289(90.1)$ & $253(9.95)$ & $2542(100)$ & \\
\hline Rural & 4467 (86.6) & $691(13.4)$ & $5158(100)$ & \\
\hline Sex of child & & & & $x^{2}=2.3971 ; p=0.122$ \\
\hline Male & 3411 (87.2) & $502(12.8)$ & $3913(100)$ & \\
\hline Female & $3345(88.3)$ & $442(11.7)$ & $3787(100)$ & \\
\hline Duration of pregnancy & & & & $x^{2}=213.5547 ; p<0.001$ \\
\hline Pre-term & $44(41.5)$ & $62(58.5)$ & $106(100)$ & \\
\hline Full term & $6712(88.4)$ & $882(11.6)$ & $7594(100)$ & \\
\hline Place of delivery & & & & $X^{2}=9.0915 ; P=0.003$ \\
\hline Home and others & $4041(86.8$ & $613(13.2)$ & $4654(100)$ & \\
\hline Health facility & 2715 (89.1) & $331(10.9)$ & $3046(100)$ & \\
\hline Total & $6756(87.7)$ & $944(12.3)$ & $7700(100)$ & \\
\hline
\end{tabular}

ratio $(\mathrm{aHR}=1.418 ; \mathrm{p}$-value $<0.05)$ than those in the North Central (the reference category) when all the variables in the model are controlled. The analysis further shows that when key predictors of infant death (especially education and wealth) are controlled, infants in the Southeast have a higher adjusted hazard ratio than those in the North Central. Living in a rural community or having a home delivery does not significantly affect the adjusted hazard ratio for infant death when education, wealth and region are controlled. Figure 1 shows the Kaplan-Meier survival estimates for wealth and education.

\section{Discussion}

Poverty, region, and poor education are the major drivers of infant mortality in Nigeria in agreement with several other studies $[5,8,15,19]$. Poverty is a factor because parents who cannot afford quality care are likely to delay use of facility-based care in the hope that their infants' health will improve with the use of traditional medicine or care with drugs purchased from Patent Medicine Vendors [29]. Seeking facility-based care often comes with the costs of transportation, hospital registration, medical tests, and drugs which caregivers may not be able to afford. Child health services are generally poorly funded 
Table 2 Cox regression model for infant death hazard ratios

\begin{tabular}{|c|c|c|c|c|}
\hline $\begin{array}{l}\text { Background } \\
\text { variables }\end{array}$ & uHR (95\% Cl) & $p$-value & $\mathrm{aHR}^{*}(95 \% \mathrm{Cl})$ & $p$-value \\
\hline \multicolumn{5}{|l|}{ Education } \\
\hline No education (RC) & 1 & & 1 & \\
\hline Primary education & $.78(0.59-1.03)$ & .084 & $1.0(.74-1.36)$ & 0.993 \\
\hline Secondaryeducation & $.46(0.35-0.58)$ & .000 & $.72(0.52-1.01)$ & 0.06 \\
\hline Higher education & $.21(0.10-0.42)$ & .000 & $.43(0.20-0.94)$ & 0.35 \\
\hline \multicolumn{5}{|l|}{ Wealth quintile } \\
\hline Lowest quintile (RC) & 1 & & 1 & \\
\hline Second quintile & $.82(0.64-1.05)$ & .113 & $.90(0.70-1.16)$ & 0.405 \\
\hline Third quintile & $.57(0.42-0.75)$ & .000 & $.74(0.54-1.02)$ & 0.063 \\
\hline Fourth quintile & $.40(0.28-0.55)$ & .000 & $.62(0.42-0.92)$ & 0.018 \\
\hline Highest quintile & $.26(0.17-0.41)$ & .000 & $.55(0.32-0.96)$ & 0.036 \\
\hline \multicolumn{5}{|l|}{ Place of residence } \\
\hline Urban & 1 & & 1 & \\
\hline Rural & $1.78(1.40-2.27)$ & .000 & $\begin{array}{l}1.19 \\
(0.90-1.57)\end{array}$ & 0.232 \\
\hline \multicolumn{5}{|l|}{ Age of mother } \\
\hline 15-19years (RC) & 1 & . & 1 & \\
\hline 20-39years & $1.01(0.69-1.48)$ & .966 & $\begin{array}{l}1.20 \\
(0.81-1.77)\end{array}$ & 0.36 \\
\hline 40-49years & $1.29(0.78-2.12)$ & .319 & $\begin{array}{l}1.34 \\
(0.81-2.23)\end{array}$ & 0.261 \\
\hline \multicolumn{5}{|l|}{ Sex of child } \\
\hline Male (RC) & 1 & & 1 & \\
\hline Female & $1.00(0.82-1.22)$ & .985 & $.98(0.81-1.20)$ & 0.868 \\
\hline \multicolumn{5}{|c|}{ Duration of pregnancy } \\
\hline Pre-term (RC) & 1 & & 1 & \\
\hline Full term & $.73(0.27-1.96)$ & .535 & $.52(0.19-1.39)$ & 0.191 \\
\hline \multicolumn{5}{|l|}{ Place of delivery } \\
\hline Home delivery (RC) & 1 & . & 1 & \\
\hline Facility delivery & $.51(0.41-0.64)$ & .000 & $.82(0.62-1.08)$ & 0.149 \\
\hline \multicolumn{5}{|l|}{ Region } \\
\hline North Central (RC) & 1 & . & 1 & \\
\hline Northeast & $1.69(1.20-2.38)$ & 0.002 & $\begin{array}{l}1.31 \\
(0.92-1.86)\end{array}$ & 0.133 \\
\hline Northwest & $1.89(1.38-2.60)$ & 0.000 & $\begin{array}{l}1.42 \\
(1.01-1.99)\end{array}$ & 0.042 \\
\hline Southeast & $1.19(0.78-1.82)$ & .423 & $\begin{array}{l}1.71 \\
(1.09-2.69)\end{array}$ & 0.02 \\
\hline South South & $.91(0.57-1.48)$ & .712 & $\begin{array}{l}1.12 \\
(0.69-1.84)\end{array}$ & 0.645 \\
\hline Southwest & $.53(0.29-0.95)$ & .034 & $.74(0.41-1.36)$ & 0.333 \\
\hline
\end{tabular}

uHR Unadjusted Ratio, aHR Adjusted Hazard Ratio, Model Chi-square $99.653, p$-value 0.000 , Proportional hazards assumption test chi square 18.21 $(p$-value $=0.1495) .{ }^{*}$ Model adjusted for education and wealth

with a significant proportion of funding coming from donor agencies, NGOs and private citizens [31]. Despite Nigeria's adoption of the Free Maternal and Child Health Care Programme, inadequate manpower and poor funding (resulting in drug stuck out, poor remuneration of workers and poor infrastructure) remains major challenges to its implementation [32]. In many rural areas where most of Nigeria's poor people are located [33] for instance, the primary healthcare centers are not functional and caregivers are often referred to higher levels of care outside their communities, further leading to additional spending on transportation and delay in reaching care [34]. For many poor households, providing care for sick infants may also be affected by their economic activities which may not be as flexible as those of richer households because the poor have little control over their work schedule and staying away from work may imply loss of income [34].

On the other hand, having little education has negative implications for caregivers' knowledge of health conditions of infants and what may be a major health risk. Education may also reduce acceptance of myths and unhealthy traditional practices as well as increase acceptance of health-promoting practices such as a high level of hygiene and sanitation in caregivers [30]. An interesting unanticipated finding from this study is that region is a predictor of infant survival when the influence of other variables in the model are controlled. Specifically, Southeast infants have a high risk of dying in infancy when the effect of education and wealth are controlled. This finding is not obvious in the DHS report which simply presents the infant mortality rates for the regions. Going by that report, the Southeast zone has one of the lowest rates (48 deaths per 1000 live births) in the country. Only the Southwest has a 'lower rate' of 43 deaths per 1000 live births [2]. Our analysis shows that there may be several factors in some regions driving infant mortality outside the variables documented by the DHS. While education and wealth may be having strong influence on child health outcomes, context specific factors such as traditional practices and health beliefs may be impacting child health negatively especially among the poor and poorly educated population of caregivers, mostly in the rural parts of the country.

An interesting finding of this study is that major biodemographic factors such as sex of child, age of mother, whether pregnancy is carried to term or delivered preterm, and place of delivery do not significantly predict infant survival when household wealth, region and education are considered. By implication, the sex of a child, the mother's age, pre-term birth and giving birth at home do not matter much in child survival if other conditions having access to financial resources, having a higher education, and not living in the Northwest or Southeast - are right. This contradicts some previous studies [9-16] that concluded that these variables matter in child survival. On the strength of our analysis, we argue that a pre-term birth stands a good survival chance if the socio-cultural context is right, if resources are available to provide 

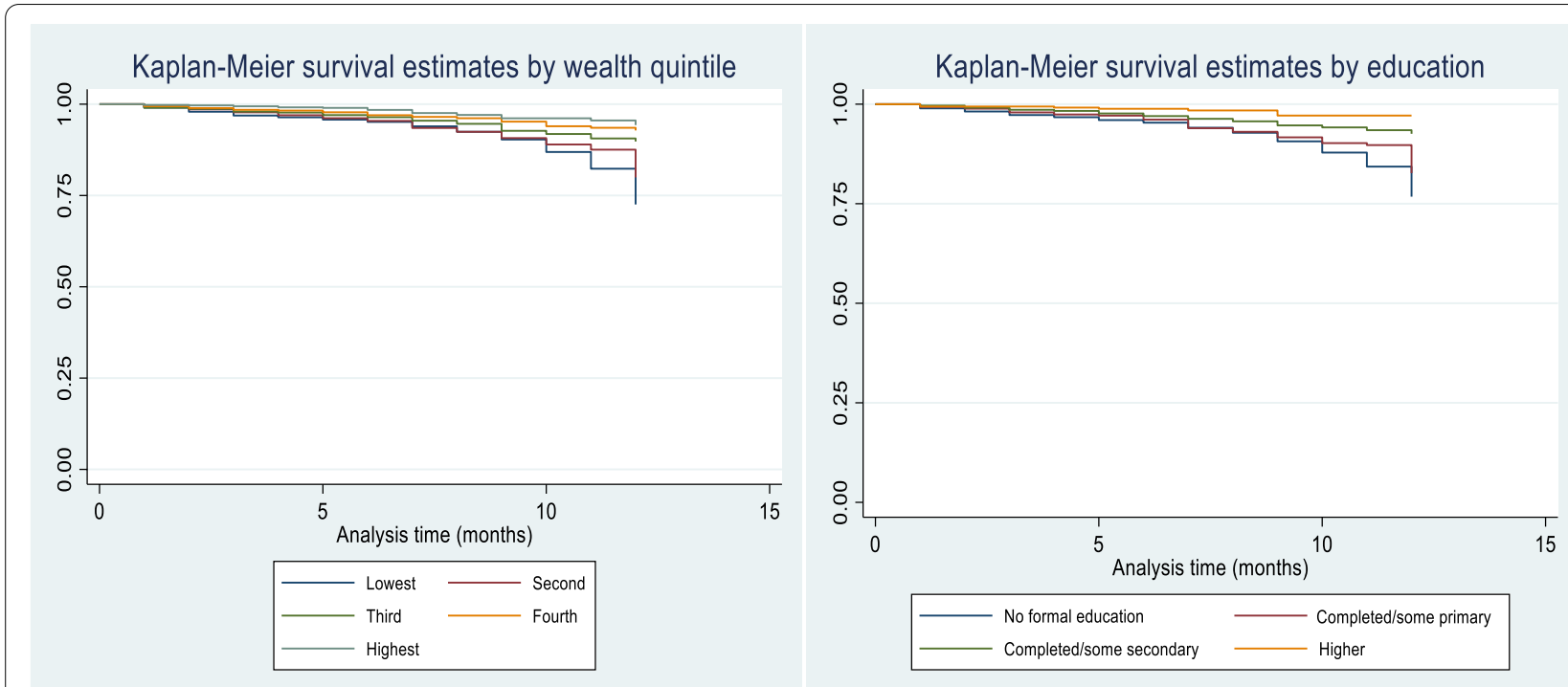

Fig. 1 Kaplan-Meier survival estimates by wealth and education

quality healthcare and nourishment for the child and the mother has higher education. In the same vein, these three factors (i.e., wealth, education, and region) have the potential of taking away differentials in the survival of male and female infants, children born in health facilities and at home, and children born to adolescent, adult, and older mothers.

\section{Strengths and limitations of the study}

The major strength of the study is the use of a large sample from a nationally representative survey data. Another strength is the complex statistical analysis carried out in the study, which gives room for controlling the effect of confounders and allows for greater reliability of the findings. Despite these strengths, the study also has some limitations that need to be considered. Maternal malaria, maternal anemia, maternal working status, father's education, father's working status, ANC attendance, iron supplementation adherence, birth weight are all potential contributors to neonatal mortality that were not explored in this study. While these are important variables with possible confounding effects, they are outside the scope of the present study. In addition, the data on time of death may not be accurate to the nearest month beyond the first year. For most children who died between their first birthday and 59 months, age at death was approximated to the nearest year (12 months), making survival analysis beyond the first year difficult or unreliable. Reported ages at death in Fig. 2 suggests heaping around 24 months, 36 months, and 48 months. With this heaping, the answers provided about time to death are not accurate and cannot be relied on for survival analysis.
This analysis was originally designed to model under-five child survival but was limited to infant survival because of the said lack of precision in documented age at death. An analysis of predictors of child death beyond the first birthday will help address issues in child death which may differ from those implicated in infant death. The reliability of the information provided in this article may also be limited by caregivers' poor recall of events.

\section{Conclusion}

The key drivers of infant mortality in Nigeria are low level of education, poverty, and underlying region specific socio-cultural/contextual factors at play in the Northern regions and surprisingly, the Southeast. Addressing the problem requires massive investment in education and women empowerment. Nigeria's basic education policy needs to be better pursued to ensure that the first 9 years of education is truly free and compulsory and education beyond this level should equally be encouraged. Although this is a long-term solution, it is the most promising solution to the problems of infant and child mortality in Nigeria. Economic empowerment is also a requirement for addressing Nigeria's infant mortality problem. Strengthening child health education for caregivers through healthcare facilities and introducing nationwide programs to provide useful information to caregivers through innovative strategies for reaching them in informal settings are equally promising strategies to addressing Nigeria's child health mortality challenge. This is because more than half of mothers do not use formal care and cannot be reached through health facilities as this study has shown. 


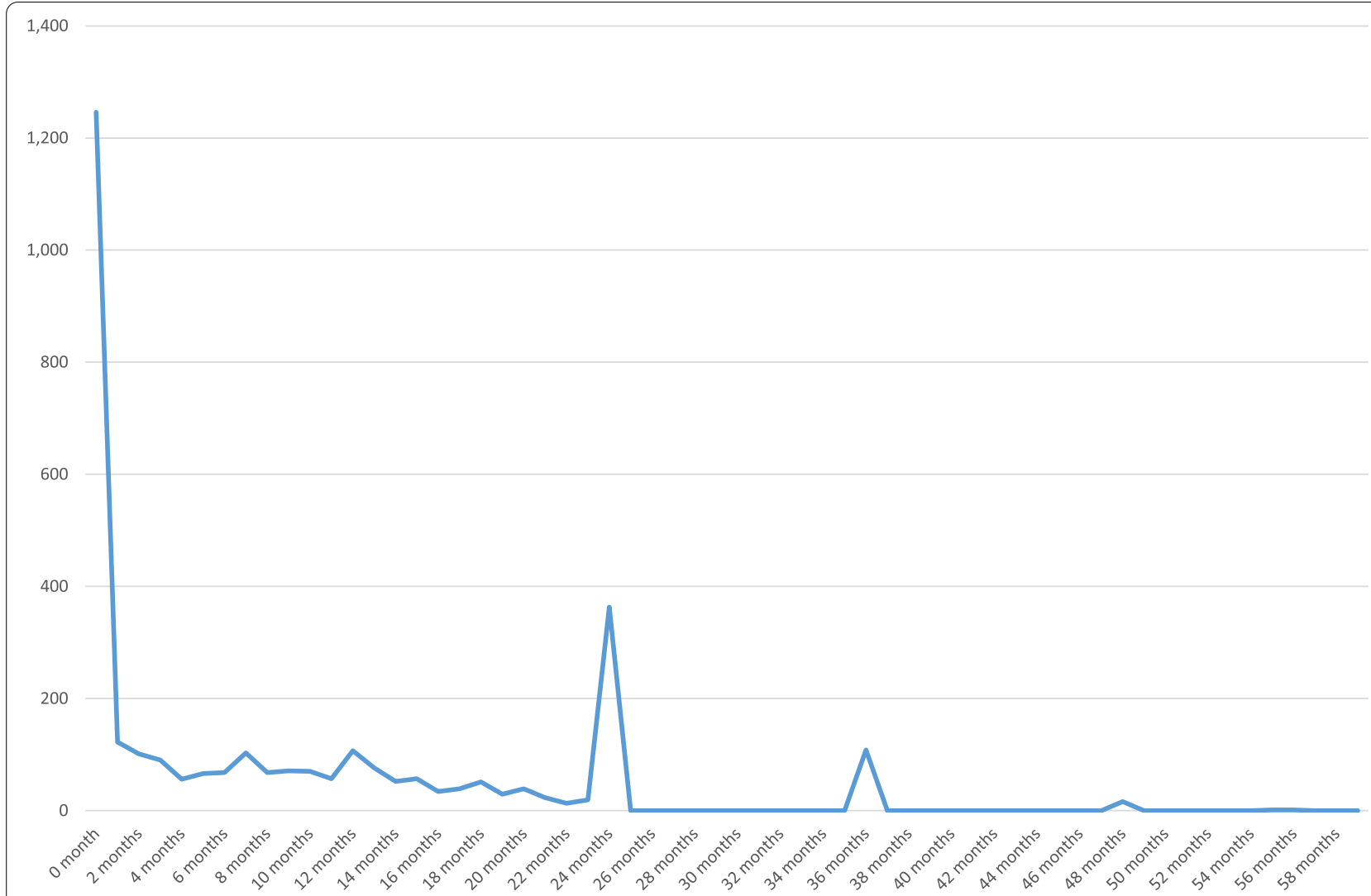

Fig. 2 Reported ages (in month) of under-five children at death

As suggested previously, there is need to target policymakers with advocacy and public health education to improve their commitment to maternal and child healthcare in Nigeria [35]. The child health policy environment in Nigeria does not suggest sufficient commitment on the part of key actors. Policymakers and programmers also need to better use evidence to improve health policies in Nigeria [36]. Programs should seek to institute focused analysis of data from studies such as the DHS, the Verbal and Social Autopsy, and the Multiple Indicator Cluster Survey for improved programming and policymaking. In the same vein, there is need for more Maternal, Newborn and Child Health intervention research [37] for improved health outcomes.

\section{Abbreviations}

aHR: Adjusted hazard ratios; Cl: Confidence interval; DHS: Demographic and Health Surveys; SDGs: Sustainable Development Goals; uHR: Unadjusted Ratio.

\section{Acknowledgements}

The authors thank the MEASURE DHS project for their support and for free access to the original data.

\section{Authors' contributions}

MK contributed to the study design, conceptualization, literature review and data analysis. IE, BOA, TO and SY provided technical support and critically reviewed the manuscript for its intellectual content. SY had final responsibility to submit the manuscript for publication. All authors read and amended drafts of the paper and approved the final version.

\section{Funding}

There was no funding for this study.

\section{Availability of data and materials}

Data for this study were sourced from Demographic and Health surveys (DHS) and available here: http://dhsprogram.com/data/available-datasets.cfm.

\section{Declarations}

\section{Ethics approval and consent to participate}

Ethics approval was not required for this study since the data is secondary and is available in the public domain. More details regarding DHS data and ethical standards are available at: http://goo.gl/ny8T6X.

\section{Consent for publication}

No consent to publish was needed for this study as we did not use any details, images or videos related to individual participants. In addition, data used are available in the public domain.

\section{Competing interests}

Sanni Yaya is editorial board member of this journal.

\section{Author details}

${ }^{1}$ Department of Sociology, University of Lagos, Lagos, Nigeria. ${ }^{2}$ School of Public Health, University of Technology Sydney, Sydney, Australia. ${ }^{3}$ School of International Development and Global Studies, Faculty of Social Sciences, University of Ottawa, 120 University Private, Ottawa, ON K1N 6N5, Canada.

${ }^{4}$ The George Institute for Global Health, Imperial College London, London, UK. 
Received: 23 October 2020 Accepted: 15 December 2021

Published online: 06 January 2022

\section{References}

1. UN Inter-agency Group for Child Mortality Estimation (UN IGME) in 2019. Child mortality estimates 2019. http://www.childmortality.org

2. National Population Commission \& ICF. Nigeria Demographic and Health Survey 2018. Abuja \& Maryland: NPC \& ICF; 2019.

3. Inter-Agency Expert Group on SDG Indicators (IAEG-SDG. SDG Indicators: Global indicator framework for the Sustainable Development Goals and targets of the 2030 Agenda for Sustainable Development. 2017. https://unstats.un.org/sdgs/indicators/indicators-list/

4. National Population Commission \& ICF. Nigeria Demographic and Health Survey 2013. Abuja \& Maryland: NPC \& ICF International; 2014.

5. Kim D, Saada A. The social determinants of infant mortality and birth outcomes in Western Developed nations: A cross-country systematic review. Int J Env Res Pub Health. 2013;10:2296-335. https://doi.org/10. 3390/ijerph10062296.

6. Khadka KB, Lieberman LS, Giedraitis V, Bhatta L, Pandey G. The socioeconomic determinants of infant mortality in Nepal: analysis of Nepal demographic survey, 2011. BMC Ped. 2015;15:152. https://doi.org/10. 1186/s12887-015-0468-7.

7. Kusneniwar GN, Mishra AK, Balasubramanian K, Reddy PS. Determinants of infant mortality in a developing region in rural Andhra Pradesh. Natl J Integr Res Med. 2013;4(4):20-6.

8. Ruiz Jl, Nuhu K, McDaniel JT, Popoff F, Izcovich A, Criniti JM. Inequality as a powerful predictor of infant and maternal mortality around the world. PLoS One. 2015;10(10):e0140796. https://doi.org/10.1371/journal.pone.0140796.

9. Adewemimo A, Kalter HD, Perin J, Koffi AK, Quinley J, Black RE. Direct estimates of cause-specific mortality fractions and rates of under-five deaths in the northern and southern regions of Nigeria by verbal autopsy interview. PLoS One. 2017;12(5):e0178129. https://doi.org/10. 1371/journal.pone.0178129.

10. Aheto JMK. Predictive model and determinants of under-five child mortality: evidence from the 2014 Ghana demographic and health survey. BMC Pub Health. 2019;19:64. https://doi.org/10.1186/s12889-019-6390-4.

11. Conde-Agudelo A, Rosas-Bermudez A, Castaño F, Norton MH. Effects of birth spacing on maternal, perinatal, infant, and child health: a systematic review of causal mechanisms. Stud Fam Plan. 2012;43:93-114.

12. Haghighi L, Nojomi M, Mohabbatian B, Najmi Z. Survival predictors of preterm neonates: hospital based study in Iran (2010-2011). Iran J Rep Med. 2013;11(12):957-64.

13. Liu L, Hill K, Oza S, Hogan D, Chu Y, Cousens S, et al. Levels and causes of mortality under age five years. In: Black RE, Laxminarayan R, Temmerman $M$, editors. Reproductive, maternal, newborn, and child health: disease control priorities, third edition (volume 2). Washington (DC): The International Bank for Reconstruction and Development / The World Bank; 2016. https://doi.org/10.1596/978-1-4648-0348-2_ch4. Chapter 4. Available from: https://www.ncbi.nlm.nih.gov/books/NBK361908/.

14. Rai SK, Kant S, Srivastava R, et al. Causes of and contributors to infant mortality in a rural community of North India: evidence from verbal and social autopsy. BMJ Open. 2017;7:e012856. https://doi.org/10 1136/bmjopen-2016-012856.

15. Tagoe ET, Agbadi P, Nakua EK, Duodu PA, Nutor JJ, Aheto JMK. A predictive model and socioeconomic and demographic determinants of under-five mortality in Sierra Leone. Heliyon. 2020;6. https://doi.org/10. 1016/j.heliyon.2020.e03508.

16. Taskaya S, Demirkiran M. Determinants of infant mortality in last two decades: a bibliometric analysis. Int J Comm Med Pub Health. 2016;3(4):77680. https://doi.org/10.18203/2394-6040.ijcmph20160731.

17. Chandwani H, Pandor J. Healthcare-seeking behaviors of mothers regarding their children in a tribal Community of Gujarat. India Electronic Physician. 2015;7(1):990-7.

18. Geldsetzer P, Williams TC, Kirolos A, Mitchell S, Ratcliffe LA, Kohli-Lynch $M K$, et al. The recognition of and care seeking behaviour for childhood illness in developing countries: a systematic review. PLoS One. 2014;9(4):e93427. https://doi.org/10.1371/journal.pone.0093427.

19. Brault MA, Ngure K, Haley CA, Kabaka S, Sergon K, Desta T, et al. The introduction of new policies and strategies to reduce inequities and improve child health in Kenya: a country case study on progress in child survival, 2000-2013. PLoS One. 2017;12(8):e0181777. https://doi. org/10.1371/journal.pone.0181777.

20. Makanju AO, Uriri AE. Survival analysis of under-five child mortality and its associated risk factors in northern Nigeria. Int J Res Inn Soc Sc. 2019;3(10):446-78.

21. Adedini SA, Odimegwu C, Bamiwuye O, Fadebiyi O, De Wet N. Barriers to accessing health care in Nigeria: Implications for child survival. Glob Health Act. 2014;7:23499. https://doi.org/10.3402/gha.v7.23499.

22. Kayode GA, Adekanmbi VT, Uthman OA. Risk factors and a predictive model for under-five mortality in Nigeria: evidence from Nigeria demographic and health survey. BMC Pregnancy Childbirth. 2012;12:10 http://www.biomedcentral.com/1471-2393/12/10.

23. Adeyele IT, Ofoegbu DI. Infant and child mortality in Nigeria: an impact analysis. Int J Econ Pract Theories. 2013;3(2):122-32.

24. Bisiriyu LA, Bankole TO, Solanke BL. Maternal and child health care service utilization and infant survival in northern Nigeria. Ife J Beh Res. 2016;8(1-2):54-71.

25. Obinna LO, Onu SE. Influence of primary health care delivery services on the health status of rural dwellers in Abia state, Nigeria. Eur J Soc Sci Stud. 2017;2(2):87-101.

26. Adedokun ST, Adekanmbi VT, Uthman OA, Lilford RJ. Contextual factors associated with health care service utilization for children with acute childhood illnesses in Nigeria. PLoS One. 2017;12(3):e0173578. https:// doi.org/10.1371/journal.

27. Olaniyan O, Sunkanmi OA. Demand for Child healthcare in Nigeria. Glob J Health Sci. 2012;4(6):129-40. https://doi.org/10.5539/gjhs.v4n6p 129.

28. Hill Z, Scheelbeek P, Schellenberg J, Hamza Y. "Everything is from god but it is always better to get to the hospital on time": a qualitative study with community members to identify factors that influence facility delivery in Gombe state. Nigeria Glob Health Act. 2020;13. https:// doi.org/10.1080/16549716.2020.1785735.

29. Dougherty L, Gilroy K, Olayemi A, Ogesanmola O, Ogaga F, Nweze C, et al. Understanding factors influencing care seeking for sick children in Ebonyi and Kogi states. Nigeria BMC Pub Health. 2020;20:746. https://doi.org/10.1186/s12889-020-08536-5.

30. Salami KK, Dumbili E, Ezeah P. Determinants of maternal and child healthcare service utilization among recently pregnant mothers in Ubulu-Okiti, Delta state Nigeria. Int J of Soc Fam. 2013;39(1-2):115-27.

31. Nnebue CC, Ebenebe UE, Uadogu PO, Onah SK, Onyeonoro UU, Ifeadike DO, et al. Availability of resources for provision of child health services at the primary health care level in Nnewi. Nig Orient J Med. 2012;24(3-40):18-27.

32. Uneke CJ, Ndukwe CD, Ezeoha AA, Urochukwu HC, Ezeonu CT. Improving maternal and child healthcare programme using communityparticipatory interventions in Ebonyi state Nigeria. Int J Health Policy Man. 2014;3:283-7. https://doi.org/10.15171/ijhpm.2014.91.

33. National Bureau of Statistics. 2019 Poverty and inequality in Nigeria. Abuja: NBS; 2019.

34. National Population Commission \& CIRCLE, Social Solutions International, Inc. 2019 Verbal and Social Autopsy Study: Qualitative component. Abuja: NPC \& CIRCLE, Social Solutions International, Inc; 2020.

35. Okonofua F, Lambo E, Okeibunor J, Agholor K. Advocacy for free maternal and child health care in Nigeria - results and outcomes. Health Policy. 2011;99:131-8.

36. Uneke CJ, Sombie I, Keita N, Lokossou V, Johnson E, Ongolo-Zogo P. An assessment of national maternal and child health policy-makers' knowledge and capacity for evidence-informed policy-making in Nigeria. Int J Health Policy Man. 2017;6(6):309-16 http://doi:10.15171/ ijhpm.2016.132.

37. Kana MA, Doctor HV, Peleteiro B, Lunet N, Barros H. Maternal and child health interventions in Nigeria: a systematic review of published studies from 1990 to 2014. BMC Pub Health. 2015;5:334. https://doi.org/10. 1186/s12889-015-1688-3.

\section{Publisher's Note}

Springer Nature remains neutral with regard to jurisdictional claims in published maps and institutional affiliations. 